\title{
Fecal calprotectin among patients infected with some protozoan infections
}

\author{
Yahya Jirjees Salman ${ }^{1 *}$, Chateen Aizideen Ali ${ }^{2}$ and Adil Abdu Allah Abdul Razaq \\ ${ }^{1}$ Department of Microbial, Kirkuk Faculty of Medicine, Iraq \\ ${ }^{2}$ Department of Basic science, College of Dentistry, Tikrit University, Iraq \\ *Corresponding author
}

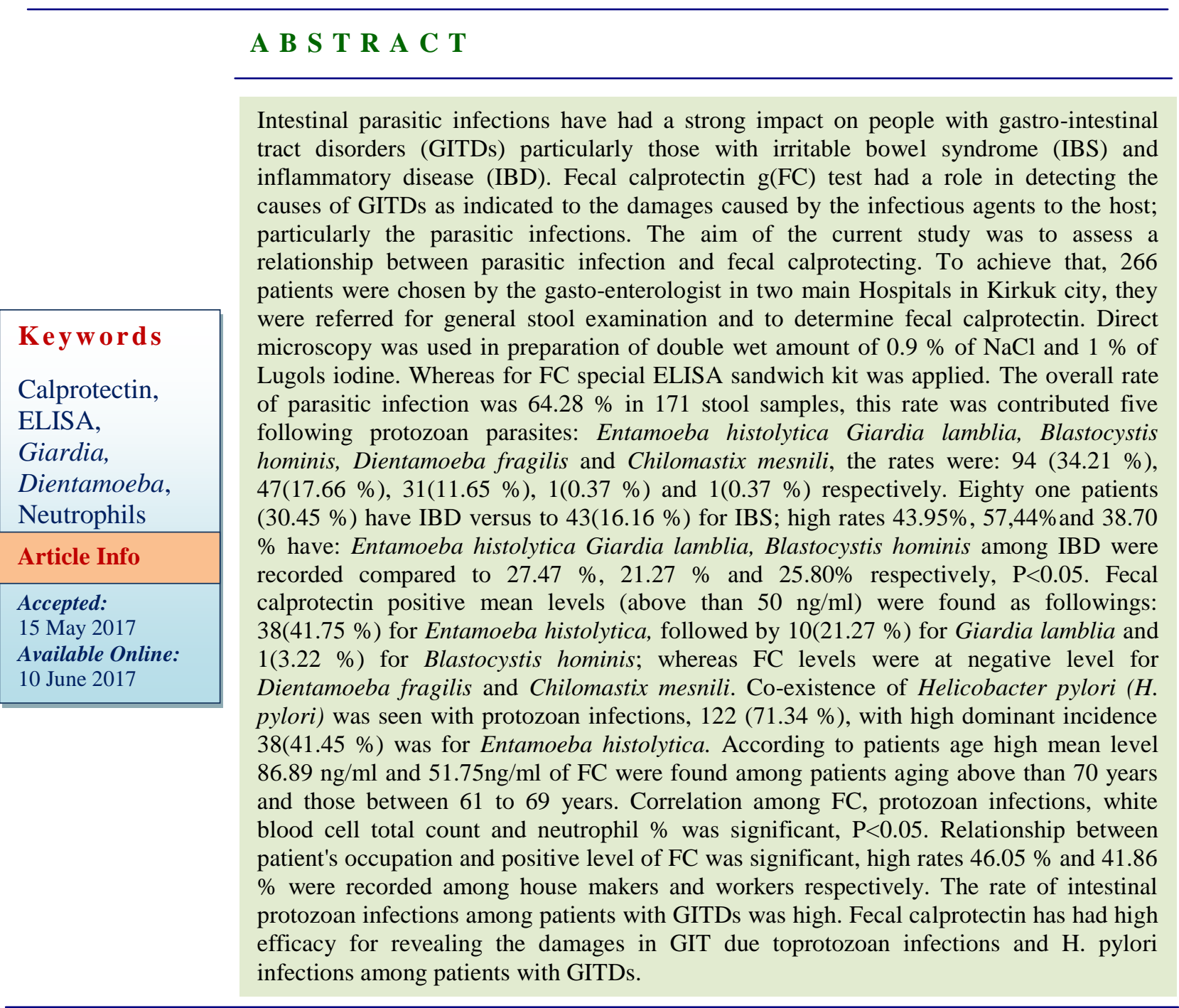

\section{Introduction}

Gastrointestinal tract (GIT) is a vital system in the body of human being, several assessor organs are joined with it. Maintaining GIT healthy from any infectious agents give raises healthy body. The more famous mysteries to this system are factorial involving; 
inflammation that can be seen as inflammatory bowel disease (IBD), either organic or inorganic types (Kaser et al., 2010). Additionally irritable bowel syndrome (IBS) that is resembles somewhat to IBD also considered as the second health problem to GIT (Fengming Y, Jianbing, 2014).Irritable bowel syndrome (IBS) is a highly prevalent gastrointestinal disorder of unknown cause with the same above symptoms (Wilson et al., 2004). Inflammatory bowel disease (IBD) is a disease of unknown cause associated with diarrhea and colonic lesions that are identified by endoscopy. However, other studies state an opposing viewpoint and it is believed that other factors probably are the causing agents of these symptoms (Kaya et al., 2007).

The etiology of each one is varying may involve some microbial agents such as invasive Entamoeba histolytica that causes ulceration of the mucosa of the large intestine (Friedman and Blumberg, 2008).

Previously Amoebiasis in Kirkuk city was described as bloody dysentery and the first scientific record of the causative agent as Entamoeba histolytica was in 1989 by (Salman and Kadir, 1999).

The rates of intestinal amoebiasis in Iraq were fluctuated depending on the number of samples, laboratory methods, seasonal assessments and other factors; the following rates were recorded: $65.20 \%$ and $30.11 \%$ in Basra, $36.26 \%$ in Nasiriya,54.6 \% in Najaf, $21.11 \%$ in Karbala, $12 \%$ in Diala, recorded by (Shenin, 2005, Al-Nassiry, 2005, Sayel, 2005,Al-Zufri, 2004 and AL-Zubaydi et al.,1997) respectively. Whereas the following rates $5.11 \% .4 .57 \%, 4.9 \%, 3.5 \%, 7.8 \%$ and $21.2 \%$ were recorded in Arab neighbor countries by (Morsy et al., 1991, Ismaiel, 2011, Hamze et al., 2004, Youssef et al., 2000, Azazy and Al-Tair 1999 and Al-Nakkas et al., 2004).
Infection with Giardia lamblia has been shown to lead to an increased prevalence of irritable bowel syndrome, as well as chronic fatigue syndrome. In a historical cohort study of patients with $G$ lamblia infection as detected by stool cysts, the prevalence of irritable bowel syndrome was $46.1 \%$ as long as 3 years after exposure, compared with $14 \%$ in controls (Wensaas et al., 2011).

Giardiasis is caused by a flagellate protozoan parasite, Giardia lamblia (order Diplomonadida, family Hexamitidae) and affects people worldwide, including people living in developing countries, but is more prevalent in areas with inadequate sanitary conditions (El-Safi,et al., 2013). It is one of the most important non-viral infections causing diarrheal illness in humans (Meyer 1990; Dib et al. 2008).

Giardia lamblia is recognized as the most common intestinal protozoan parasite infecting humans in Iraq (Abd-Alzahra et al., 2012) particularly in Kirkuk Province (Salman and Mustafa, 2013). These diseases are often overlooked during routine parasitological or serological testing of intestinal parasites (Salman and Salih, 2013). Depending on availability of equipment, reagents, technical experience, considerations of time, and cost, there are several methods for the detection of giardiasis (Ndao, 2010). Microscopic examination of stool samples, either direct or concentrated, for the recovery of G.lamblia both stages trophozoites and cysts (CLSI,2005).

The recent crisis and violence lead to massive population movement, and presence of over 1,500,000 internal displaced in Iraq (Xiao et al., 1999). The displacement of populations from different communities often brings people into proximity either dueto increased concentrations of displaced populations and also increased density in terms of the living 
environment (Salman et al., 2015 a). If one group is a carrier of illness, disease outbreaks reflecting endemic pathogens circulating within the community may occur (Watson et $a l ., 2007)$. Because of the internally displaced persons are at high risk for emerging parasitic infections, since in most cases, they have a history of poor utilization of medical care and vaccination, living conditions of low socioeconomic status and a high possibility to be carrying symptomless diseases, so it is important to carry out an assessment for diarrheal risk factors particularly intestinal parasites with an emphasis on Giardia lamblia and to avoid any health risks.

Blastocystis hominis is the most common intestinal parasite in humans and many other animals (Windsor et al., 2002). Blastocystis, an unusual anaerobic, single-celled stramenopile, is a remarkably successful intestinal parasite of a vast array of host species including humans (Stensvold, 2013). Infections with this organism are spread worldwide and it is often the most frequently isolated protozoan in parasitological surveys (Boorom et al., 2008; Chandramathi et al., 2010; Roldan et al., 2009). In developing countries, $B$. hominis has a higher prevalence (30 to $50 \%$ ) in comparison with developed countries (1.5 to $10 \%$ ) (Li et al., 2007). The pathogenicity of $B$. hominis still has been debated. A report supporting the pathogenic potential of this parasite (Ok et al., 1999); that can be found in patients with or without gastrointestinal symptoms. Some of the symptoms associated with Blastocystis infection include abdominal pain, constipation, and diarrhea, alternating diarrhea and constipation and others (Qadri et al., 1989).

Morphologically the parasite has four phases: vacuolar, granular, amoebic and cystic phase. The later phase has been considered a dominant phase found in the environment (soil and water) so, it acts as a vehicle for transmitting the parasite into the host. Human to human and human to animal transmission was not obvious (Yoshikawa et al., 2004). Diagnosis of $B$. hominis overlaps with other causatives of diarrhea specially the size of the cysts that measures 3 to $10 \mu \mathrm{m}$ which is close to oocyst of Cyclospora, Entamoeba histolytica and other protozoan parasites (Tan, 2004). Routinely direct microscopy by preparing of wet preparation of Lugol's iodine, fecal smear staining with trichrome stain can demonstrate B. hominis (Tan, 2008),

Information about B. hominis in Iraq was not clear, except the study was carried out in south part of Baghdad by Raof and AbdulRaham (2011) and in Kirkuk karyaghdi (2013) when they carried out diagnostic study on some intestinal parasites, via which $B$. hominis contributed $3.6 \%$.In Kirkuk city-Iraq Salman in 2015was carried on a comparative study using direct microscopy and ELISAcopro antigen test for detecting Blastocystis hominis rate among peoples with irritable bowel syndrome, he found the all rate of Blastocystosis $58.22 \%$ This rate was contributed $59.44 \%$ and $58.99 \%$ for direct microscopy finding and ELISA testing. Statistically the differences between two methods was not significant.

Dientamoeba fragilis is a species of singlecelled excavates found in the gastrointestinal tract of some humans, pigs and gorillas. It causes gastrointestinal upset in some people, but not in others. Dientamoeba fragilis is a type of trichomonad. Trichomonads are flagellated organisms, but $D$. fragilis lacks flagella (Chudnovesky, 2016) having secondarily 'lost' them over evolutionary time. Thus, it is an amoeba of flagellate ancestry. In point of ultrastructural and antigenic view, Dientamoeba is reclassified as a flagellate. It is an important cause of travelers' diarrhea, chronic diarrhea, fatigue and, in children, 
failure to thrive. There is a continuous debate where $D$. fragilis is considered to be a harmless organism or a pathogenic parasite (Windsor JJ, Macfarlane, 2005).

Infection with D. fragilis, called dientamoebiasis, is associated variously with symptoms of abdominal pain, diarrhea, weight loss, nausea, fatigue and fever. In one study, D. fragilis was identified in $0.9 \%$ of patients observed. Its coincidence with enterobiasis, caused by E. vermicularis, has been reported (Stark et al., 2005) in another study, eosinophilia was present in half of the infected children participating in the case. $D$. fragilis does not penetrate the host tissue directly; therefore, some of these symptoms may be caused from irritation which then leads to colonic motility (Johnson, 2016). Infection can occur at any age; however, the most common ages that have been reported are children 5-10 years old (Mack, 2016)

In order to diagnose the parasite, patients are required to provide (multiple) fresh stool samples that have been preserved for parasite examination. The multiple samples are required because of parasite detection being difficult, therefore, a sample might be obtained each day to help increase the sensitivity Patients can also be tested for $E$. vermicularis since the two parasites are known to coincide. (Stark et al., 2005)

Unlike the majority of parasitic infections, $D$. fragilis is more prevalent in well-developed countries as opposed to disadvantaged and resource poor nations. (Lagacé-Wiens et al., 20006) The parasite is also endemic in crowded communities (i.e institutions), populations with unsatisfactory sanitation conditions, and individuals who travel to underprivileged countries (Mack, 2016). Globally, the prevalence of $D$. fragilis ranges from $0.3 \%$ to $90 \%$, occurring in multiple countries, including many urbanized cities such as Los Angeles, California and Sydney, Australia. Recently, $D$. fragilis was considered to be more prevalent than Giardia, thus leading to better diagnostics (LagacéWiens et al., 20006).

The lifecycle of this parasite has not yet been completely determined, but some assumptions have been made based on clinical data. Recently, a cyst stage has been reported (Munasinghe, 2013) although it is yet to be independently confirmed. If true, $D$. fragilis is probably transmitted by the fecal-oral route. Prior to the report of this cyst stage in the lifecycle of Dientamoeba, transmission was postulated to occur by helminth eggs (e.g., Ascaris, Enterobius spp.). The rationale for this suggestion was that $D$. fragilis is closely related to the turkey parasite Histomonas, which is known to be transmitted by the eggs of the helminth Heterakis. Since $D$. fragilis is known to frequently coinfect with $E$. vermicularis, this leads to the assumption that $E$. vermicularis is a possible vector and mode of transmission (LagacéWiens et al., 2006).Reports on Dientamoeba fragilis were very rare in Iraq, only one record of this parasite was recorded in Kirkuk Province by (Salman, et al., 2015 b), who report $0.12 \%$ from a total of 780 stool samples collected from Iraqi displaced peoples.

Chilomastix mesnili is of cosmopolitan distribution, although found more frequently in warm climates. It is thought to be nonpathogenic although the trophozoite has been associated with diarrhoeic stool. The cost is 6$9 \mu \mathrm{m}$ contains a large single nucleus with a large karyosome. It has a prominent side knob which gives it a characteristic lemon shape. The cytosome is evident with a curved shepherd's crook fibril. The trophozoites of C. mesnili are pear shaped and measure 10$20 \mu \mathrm{m}$ in length. It has 1 large nucleus with a 
small karyosome and 3 flagella which extend from the nucleus at the anterior end of the parasite. A distinct oral groove or cytosome can be seen near the nucleus. It moves in a directional manner. Laboratory diagnosis is based on finding lemon shaped cysts can be seen in a formol-ether concentrate stool samples. Motile organisms can be seen in a wet preparation of a fresh stool however the characteristic morphology is evident in a permanently stained preparation. The records of this parasite were not obvious, because mostly it was considered as non-pathogen, so it was often missed, the two following rates: $0.239 \%$ and $0.126 \%$ of Chilomastix mesnili were recorded in Kirkuk by (Salman et al., 2016 and Salman et al., 2015 b).

Helicobacter. Pylori (H. pylori) is a gramnegative bacterium that is estimated to infect approximately half of the world population. It colonizes the gastric mucosa of its human host where it may give rise to symptoms such as recurrent peptic ulcers and chronic gastritis, and has also been associated with gastric cancer (Suerbaum and Josenhans, 2007) The prevalence of $H$. pylori is high in low-income countries and it was recently shown to colonize $46 \%$ of children age $1<3$ years in an area of urban Kampala, Uganda (Hestvik et al., 2007).

Fecal calprotectin (FC) antibody is that antibody produced by the white blood cell neutrophils when it was in challenges with the pathogens that causes IBD (Quail et al., 2009). That antibodies bound to serum albumin can be assessed serologically as antigen antibody-complex color formation, that to be easily determined by Elisa reader. Some authors stated that the FC antibody level above than $50 \mathrm{ng} / \mathrm{ml}$ was indicating to severe damage in GIT which demands endoscopy for getting more details about the causative agents. While FC levels below 50 $\mathrm{ng} / \mathrm{ml}$ may indicate other etiological agents that not demands endoscopy application (van Rheenen et al., 2010).

Furthermore Calprotectin is a neutrophil cytoplasmic calcium-binding protein that is also found in monocytes and early stage macrophages. Its degranulation inside the intestinal lumen occurs as a response to local inflammation (Foell et al., 2009). Detection of calprotectin in stool is currently used across gastroenterology practices to aid diagnostically in distinguishing between inflammatory bowel disease and other noninflammatory ailments, thereby decreasing the number of unnecessary endoscopies performed. It is also used as a validated marker for disease activity and response to treatment (Komraus ET: 2012) and (Sherwood, 2012). Its use in enteric infections is gaining recognition, particularly as a correlative marker for clinical severity in infectious diarrhea from both viral and bacterial etiologies (Chen et al., 2012).

From geographical view, Kirkuk Province is located in the North of Iraq and its location was very important because it acts as a passage from Northern to capital and other Provinces. Due to war in 2013 in Al-Hawija town and consequence war in other neighboring Provinces, most of peoples were migrated and attends to Kirkuk city, which becomes a more crowd. The migrated or displaced Iraqi people were, habitat old buildings, under construction, schools, they lifted under very poor hygienic condition. Moreover to continuous water interruption in this Province since about 10 years ago. All of these factors were worsening the doctors and scientific workers in this Province to predict the increasing in the rate of infectious agents and increasing the incidence of some diseases in particular diarrheal, respiratory, cutaneous and parasitological diseases. Diagnostic laboratory studies concerning GIT in particular IBD and IBS among patients in 
Kirkuk province are very rare, except two studies carried on by(Salman,2015) on the relationship between IBS and Blastocystis hominis and (Al-Jubori et al.,2015) who studied the possible role of Blastocystis hominins during IBD. On the other hand, there is no real data or studies about protozoan parasitic infection prevalence among IBD and IBS patients and for the first time FC antibody in Kirkuk city was undertaken as a laboratory test. For these reasons the current study was conducted to assess gastro-intestinal disorders (GIDs), to determine the rate of some common protozoan infections and to detect the relationship between fecal calprotectin and protozoan infections.

\section{Materials and Methods}

\section{Ethics statement}

The study was approved by the Kirkuk Research and Publication Committee of Kirkuk Health directorate, and by the respective Hospital authorities at the two study hospitals. Written informed consent was obtained from the parents or guardian on behalf of all the patients enrolled in the study.

\section{Study population}

From the $1^{\text {st }}$ of July/ 2016 till the 31 th of January /2017, a total of (266) Stool and blood samples from 145 male and 121 female were collected, who attends gastro-enterology clinics in both Azidi teaching Hospital and Kirkuk general Hospital in addition to patient selection from private clinics and medical labs in particular Ibn-Nafies private medical lab in Kirkuk city. Patients' ages were ranged from 1 year to over than 70 years. According to occupations, they were classified into five groups. Most of them were with gastointestinal disorders (GIDs); they divided into IBS, IBD and control group. Their compliances were abdominal cramps, epigastric pain, and dailydiarrhea, diarrhea altered with constipations, weight loss, and fatigues. Diarrhea was defined as three or more watery stools within 24 hours. An episode of diarrhea was considered over when two consecutive days pass without diarrhea. An episode of acute diarrhea was defined as duration between 24 hours and less than 14 days. Persistent diarrhea was defined as diarrhea for 14 days or more. Control $(\mathrm{N}=$ 51) was patients with no history of diarrhea during the last month prior to enrollment. A standardized questionnaire and patient files were used for collection of demographic and clinical information.

\section{Samples collections}

From each patient stool and blood samples were collected. Stool samples were collected in clean and dry containers. Each specimen was divided into three fractions: first was kept in the cold box for $\mathrm{H}$. pylori investigation, second fraction was mixed $5 \mathrm{ml}$ of sterile $\mathrm{NaCl}$ solution then kept for protozoa motility investigation. Whereas $5 \mathrm{ml}$ of Potassium chloride solution was added to the third fraction for complete parasite microscopy. All the stool samples were kept in refrigerator till to processing, this procedure was done according to (Salman, et al., 2015 a). Five ml of venous blood was aspirated and transferred in to EDTA tube (Contains anti-coagulant)., inverted several times to prevent clots. Blood samples were used for checking complete blood count (CBC), including total white blood corpuscle count (WBCs) and differential count involving neutrophils percentage. Also the same sample was used for detecting $\mathrm{ABO}$ blood group and Rhesus factor for each patient using the tube agglutination test., In case predicting delay sample processing blood samples were kept in refrigerator to less than 24 hours. 


\section{Samples Processing}

\section{Stool examination}

Direct wet, double preparation of $\mathrm{NaCl} 0.9 \%$ and $1 \%$ of Lugols iodine was applied for each stool specimen. For each specimen 3 trials of repeated examination were achieved in the same day to exclude negative results. This method was done according to (Salman, 2015a) and (WHO, 1991).

\section{The second fraction}

The stool samples was introduced for direct agglutination between Helicobacter pylori in the stool as antigen with immobilized monoclonal antibodies bound on the chromatography pad inside the special cassette containing enzymatic conjugate (HRP) and Substrate as (TMB)., the method briefly started by transporting small portion of stool sample in the small container containing buffer, mixed thoroughly then about 2 drops (80 microliters) were inserted in to specific hole. Before 10 minutes the pink to red bands (control and test) mean positive for H.pylori while appearing only control band and means negative result. This method was done according to the leaflet of Bio-zek companyNetherland.

\section{Quantitative fecal calprotectin ELISA test}

This ELISA kit was purchased from Epitope Diagnostic Int (EDI) company-USA. This ELISA is designed, developed and produced for the quantitative measurement of human calprotectin in stool samples. The assay utilizes the two-site (Sandwich) technique with two selected antibodies that bind to different epitopes of human calprotectin.

Assay standards, controls and patient samples are added directly to the wells of a micro-titer plate that is coated with antibodies to calprotectin. After a short incubation period, the plate is washed and horseradish peroxidase (HRP) -conjugated human calprotectin specific monoclonal antibody is added to each well. After the second incubation period a sandwich of solid - phase antibody -human calprotectin - HRPconjugated monoclonal antibody is formed. The unbound monoclonal antibodies and buffer matrix are removed in the subsequent washing step. For the detection of this immune-complex, the well is then incubated with a substrate solution in a timed reaction and then measured in a spectrophotometric micro-plate reader. The enzymatic activity of the immune-complex bound to the wall of each micro-titer well is directly proportional to the amount of human calprotectin in the test sample. A standard curve is generated by plotting the absorbance versus the respective human calprotectin concentration for each standard on a point-to-point or 4-parameter curve fitting. The concentration of fecal human calprotectin in test samples was determined directly from this standard curve. Result below $50 \mathrm{ng} / \mathrm{ml}$ was considerd negative.

\section{Statistical analysis}

Values are expressed as percentages, averages and mean \pm SE were arranged in tables. Variances between study parameters were checked by using chi-square test and t-student test as significant when the differences between two analyzed parameters were at $\mathrm{P}<0.05$.

\section{Results and Discussion}

Five species of intestinal parasites were recorded during the examination of a total of (266) stool samples using direct wet, double preparations of $0.85 \%$ of $\mathrm{NaCl}$ and $1 \%$ of lugols iodine stain, table(1). The common recorded parasites involve: Entamoeba 
histolyticain 91 specimens, the rate was 34.21 $\%$, followed by Giardia lamblia 47(17.66\%), Blastocystis hominisin $31(11.65 \%)$ and $1(0.37 \%)$ for each of the following equally Dientamoeba fragilis and Chilomastix mesnilli, $\mathrm{P}<0.05$. Co-existence of protozoan infection was highly associated to H.pylori positivity. The following rates of H.pylori 75 $(82,41 \%), 37(78.72 \%)$ and $10(32.25 \%)$ were recorded among the positive samples for Entamoeba histolytica, Giardia lamblia and Blastocystis hominis respectively, $\mathrm{P}<0.05$

In the same table, the frequencies of positive FC were assessed via which the following results were recorded: $38(41.75 \%)$ of FC were positive among stool samples positive for Entamoeba histolytica, followed by 10(21.27\%) for Giardia lambliaand 1(3.22) for Blastocystis hominis, $\mathrm{p}<0.05$. Samples positive for Dientamoeba fragilis and Chilomastix mesnilli reveal negative for FC.

Frequency of protozoan parasites, according to GITDs was clarified in the table -2 via which from a total of 171(64.28 \%) of samples were positive for protozoan parasites; only $81(30.45 \%)$ patients were with IBD, 43(16.16) with IBS and 47(17.17\%) were with other etiology. Also from a total of 47(17.66 \%) samples positive for Entamoeba histolytica, 40 (43.95\%) have IBD versus to $25(27.47 \%)$ and $26(28.57 \%)$ with other etiology or normal. Regarding Giardia lamblia; 27(57.44\%), 10(21.27 \%) and 10(21.27 \%) were IBD, IBS and other etiology or normal respectively. While Blastocystis hominis were recorded as IBD $12(38.70 \%)$ followed by $8(25.80 \%)$ and $11(35.48 \%)$ for IBS and for other etiology or normal. Moreover Dientamoeba fragilis and Chilomastix mesnili both were recorded among IBD. Statistical analysis was showed strong significant relationship between types of GITDs and Protozoan infections, $\mathrm{P}<0.05$.

The correlation between the mean of white blood cell numbers in cells $/ \mathrm{mm}^{3}$ and the high and low fecal calprotectin levels was illustrated in figures -2 , the results of the present study clarified that the mean numbers of white blood cells in specimens with high calprotectin concentration was 12119 cell $/ \mathrm{mm}^{3}$ versus to $5629 \mathrm{cell} / \mathrm{mm}^{3}$ in specimens with low calprotectin concentration, $\mathrm{P}<0.05$.

The relationship between patients age and the mean of fecal calprotectin levels was shown in figure - 1, via which the result of the present study showed that higher FC 86.89 $\mathrm{ng} / \mathrm{ml}$ was among patients agingover, 70 years, $51.75 \mathrm{ng} / \mathrm{ml}$ among $61-70$ years, and $40.62 \mathrm{ng} / \mathrm{ml}$ among 31-40 years.Followed by $40.03 \mathrm{ng} / \mathrm{ml}, 38.35 \mathrm{ng} / \mathrm{ml}$, and $38.17 \mathrm{ng} / \mathrm{ml}$ among 41-50 years, 0-10 years and 51-60 years respectively. And in the same figures the mean of fecal calprotectin levels 37.16 $\mathrm{ng} / \mathrm{ml}$ detected in 11-20 years, followed by $32.47 \mathrm{ng} / \mathrm{ml}$ in $21-30$ years.

The correlation between the mean number of neutrophil cells $/ \mathrm{mm}^{3}$ and the high and low fecal calprotectin levels was arranged in figures -3 ; the results showed that the mean numbers of neutrophils in high calprotectin concentration were 6638 cells $/ \mathrm{mm}^{3}$ and the versus 4892 cells $/ \mathrm{mm}^{3}$ was found to be low calprotectin concentration.

The mean rate of fecal calprotectin in relation to patients' occupation was showen in figure 4 , via which the specimens belong to house makers show the highest average rate 46.05 $\mathrm{ng} / \mathrm{ml}$ of FC, followed by the workers that the mean levels was $41.86 \mathrm{ng} / \mathrm{ml}$, and 38.51 $\mathrm{ng} / \mathrm{ml}, 36.08 \mathrm{ng} / \mathrm{ml}, 33.76 \mathrm{ng} / \mathrm{ml}$ in children, students and officers respectively. $\mathrm{P}<0.05$.

Intestinal parasitic infections have had a strong impact on the status of the GIT. Symptoms of amoebiasis can overlap with symptoms of the inflammatory bowel disease (IBD). It can lead to difficulties in the diagnosis and treatment of IBD (Hansen and 
Lund 1998). In that case the diagnosis and management of inflammatory bowel disease can be challenging as certain infections can mimic IBD and lead to a misdiagnosis. Because of the increasing use of corticosteroids, immunosuppressive drugs and biological agents in the risk of opportunistic infection including amoebiasis are also higher in IBD patients. The role of the physician lies not only in the diagnosis and management of IBD but also in the ability to prevent, recognize and treat infections.

Amoebiasis can exacerbate symptoms of IBD and has unfavorable influence on course of the disease and therapy. Inadequate mucosal immune response on the intraluminal antigenic components is essential in the IBD pathogenesis (Kaser et al., 2010). Finding of $43.21 \%$ of amoebiasis in the current study was not in agreement with those $65.20 \%$ and $54.6 \%$ recorded in Basra and Al-Nasiriya-Iraq respectively, also it was higher than those recorded in neighboring country as the following rates $5.11 \% .4 .57 \%, 4.9 \%, 3.5 \%$, $7.8 \%$ and $21.2 \%$ were recorded in Arab neighbor countries by (Morsy et al., 1991, Ismaiel,2011,Hamze et al.,2004,Youssef et al., 2000, Azazy and Al-Tair 1999 and AlNakkas et al., 2004). This high rate of intestinal amoebiasis reflects the highest level of contamination in this Province, particularly of water. On the other hand, this rate may not refer to real infection with Entamoeba histolytica, because in the nature water mostly contain high numbers of Entamoeba dispar as it seems very similar to Entamoeba histolytica, except it was not invasive. This explanation should be excluded here because most of Amoebic cases in the current study were IBD(Invasive) $43.95 \%$.Variances in the rates might be due to differences in sample size, type of laboratory method, type of the study group and design of the study, because current study was designed for GIDs not for general population.

Table.1 Distribution of intestinal protozoan parasites among patients positive for Helicobacter pylori in relation to calprotectin positive levels

\begin{tabular}{|c|c|c|c|}
\hline Parasite species & $\begin{array}{l}\text { Positive } \\
\text { No. }(\%)\end{array}$ & $\begin{array}{l}\text { H.pylori +ve } \\
\text { No. }(\%)\end{array}$ & $\begin{array}{l}\text { Calprotectin } \\
\text { antibody +ve }\end{array}$ \\
\hline Entamoeba histolytica & $91(34.21){ }^{* * *}$ & $75(82.41)^{* * *}$ & $38(41.75)^{* * *}$ \\
\hline Giardia lambilia & $47(17.66)$ & 37 (78.72) & $10(21.27)$ \\
\hline Blastocystis hominis & $31(11.65)$ & $10(32.25)$ & $1(3.22)$ \\
\hline Dientamoeba fragilis & $0.37)(1$ & $0(0.00)$ & $\mathbf{0}(\mathbf{0 , 0 0 )}$ \\
\hline Chilomastix mesnilli & $1(0.37)$ & $0(0.00)$ & $0(0.00)$ \\
\hline Total & $171(64.28)$ & $122(71.34) D$ & $49(28.65)$ \\
\hline
\end{tabular}

* Calprotectin +ve level is from $50 \mathrm{ng} / \mathrm{ml}$ up to above. Total examined stool samples $=266 . * *: \mathrm{P}<0.05[(E$. histolytica $\mathrm{P}=0.864, \mathrm{P}<0.05$ ). (G. lamblia $\mathrm{P}=0.718, \mathrm{P}<0.05$ ). (B.hominis $\mathrm{P}=0.498, \mathrm{P}>0.05$. Not Significant). (D.fragilis \& Ch. mesnili / No significant due to unique value).] 
Table.2 Frequencies of Protozoan parasites and type of Gastro-intestinal disorders

\begin{tabular}{|c|c|c|c|c|c|c|c|c|}
\hline \multirow[t]{2}{*}{ Protozoan parasites } & \multicolumn{2}{|r|}{ IBD } & \multicolumn{2}{|r|}{ IBS } & \multirow{2}{*}{\multicolumn{2}{|c|}{$\begin{array}{r}\text { Normal or other } \\
\text { etiology } \\
\text { No } \%+\text { ve }\end{array}$}} & \multicolumn{2}{|r|}{ Total } \\
\hline & No & $\%+v e$ & No & $\%+v e$ & & & No & $\begin{array}{r}\% \\
+ \text { ve }\end{array}$ \\
\hline $\begin{array}{r}\text { Entamoeba } \\
\text { histolytica }\end{array}$ & 40 & 43.95 & 25 & 27.47 & 26 & 28.57 & 91 & 34.21 \\
\hline Giardia lamblia & 27 & 57.44 & 10 & 21.27 & 10 & 21.27 & 47 & 17.66 \\
\hline Blastocystis hominis & 12 & 38.70 & 8 & 25.80 & 11 & 35.48 & 31 & 11.65 \\
\hline $\begin{array}{r}\text { Dientamoeba } \\
\text { fragilis }\end{array}$ & 1 & 100 & 0.0 & 0.0 & 0.0 & 0.0 & 1 & 100 \\
\hline Chilomastix mesnili & 1 & 100 & 0.0 & 0.0 & 0.0 & $\mathbf{0 . 0}$ & 1 & 100 \\
\hline $\begin{array}{r}\text { Total } \\
\end{array}$ & 81 & 30.45 & 43 & 16.16 & 47 & 17.66 & 171 & 64.28 \\
\hline
\end{tabular}

Total examined stool samples: $266 \mathrm{P}<0.05$

Fig.1 Relationship between patient Ages and Fecal Calprotectin Concentration

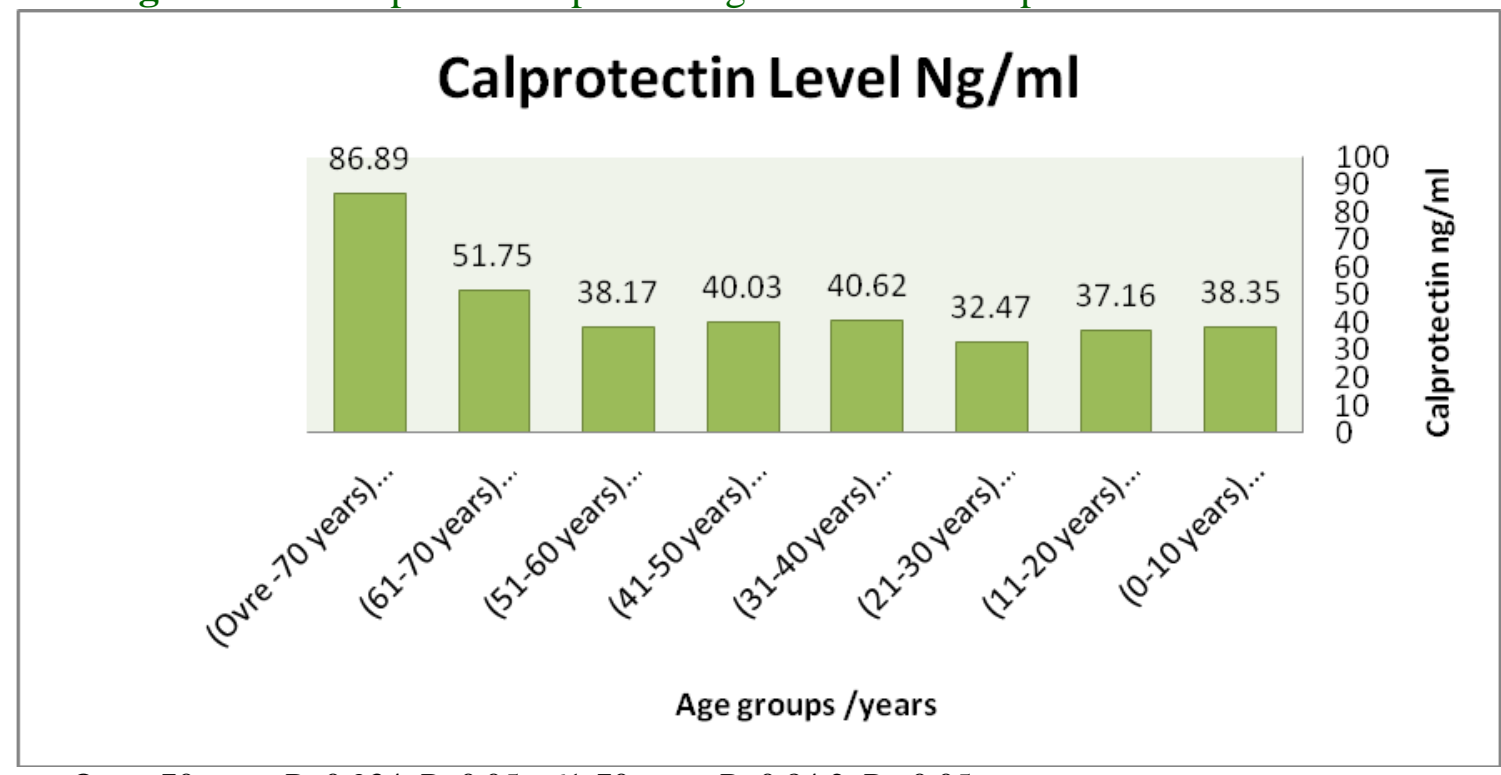

Over -70 years $\mathrm{P}=0.934, \mathrm{P}<0.05 .-61-70$ years $\mathrm{P}=0.84 .2, \mathrm{P}<0.05$.

Fig.2 Correlation between number of white blood cell / $\mathrm{mm}^{3}$ and high and low fecal Calprotectin levels

\section{W.B.Cs No. Cell/mm3.}

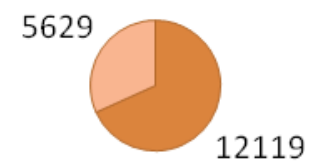

$\square$ High CAL levels $\square$ Low CAL levels

$\mathrm{P}<0.05$ (-LOW CAL $\mathrm{P}=0.523, \mathrm{P}<0.05)$. (-High CAL $\mathrm{P}=0.837, \mathrm{P}<0.05$ ) 
Fig.3 Correlation between Number of Neutrophil cell / $\mathrm{mm}^{3}$ and High Calprotectin levels Results and Low Calprotectinlevels Results

\section{Neutrophil No. Cell/mm3.}

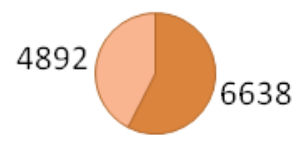

Low FC level, $\mathrm{P}=0.588, \mathrm{P}<0.05$ High FC level, $\mathrm{P}=0.721=\mathrm{p}<0.05$

Fig.4 The Correlation between Fecal Calprotectin Concentration and the Patients Occupations

\section{Calprotectin Level $\mathrm{Ng} / \mathrm{ml}$}

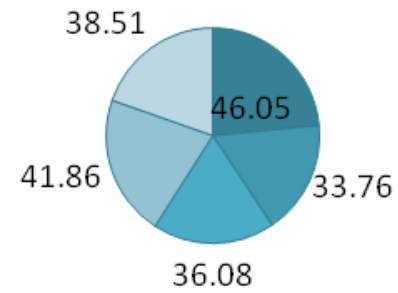

\section{- House Makers Calprotectin levels \\ Students Calprotectin levels \\ $\square$ Childe Calprotectin levels}

Officers Calprotectin levels

$\mathrm{P}<0.05$ [(H.M. $\mathrm{P}=0.913, \mathrm{P}<0.05)$, (Officer $\mathrm{P}=0.497, \mathrm{P}>0.05)$,

(Students $\mathrm{P}=0.643, \mathrm{P}<0.05)$, (Workers $\mathrm{P}=0.885, \mathrm{P}<0.05$ ). and (Children $\mathrm{P}=0.855, \mathrm{P}<0.05)]$.

The second protozoan parasite that found in 47 samples with the rate $17.66 \%$ was Giardia lamblia. In acute cases the picture of liquid diarrhea is mimic to that of IBS, color and even the odor of the positive Giardia stool samples are the same. (Salman et al., ;2016). The finding rate of giardiasis in current study was not agreed those $7.06 \%$ and 10.31 $\%$ recorded in Kirkuk by Salman, et al., 2015b and Salman et al., 2016 respectively in the same Province. Interpretation to this high rate might be due to type of the patients as $21.27 \%$ of patients has IBS, while in their studies they take general patients. This finding was lower than $46.3 \%$ recorded among IBS patients by Wansaas et al., 2012).
Giardiasis rates in other studies (Abd-Alzahra et al., 2012, Salman and Mustaf, 2013. Salman and Salih, 2013, whom they record high rates of giardiasis also not agreed the Giardia rate in the current study.

While in chronic cases giardiasis is resemble to IBD during which epi-gastric pain is common in addition to other sequels. Pathogenic infections such as Clostridium difficile and parasites such as Giardia lamblia are reported in $5.7 \%$ and $6.5 \%$, respectively, of people with symptoms attributable to IBS (Clayton et al.,2012.) and (Grazioli et al., 2006) and are readily detected in the fecal specimens using established techniques such as culture and light microscopy. 
Blastocystis hominis, the most common human intestinal parasite, was long thought to be non-pathogenic. (Poirier et al., 2012) Some (but not all) recent studies, however, have demonstrated a significant increased prevalence of Blastocystis hominis in IBS patients compared with controls, and at least one authority has recommended treatment with metronidazole in the face of a positive identification of the organism and a symptomatic patient.(Grazioli et al., 2006)

In the present study, parasites as a whole accounted for $11.65 \%$ of abnormal values. The single most commonly-identified organism was Blastocystis hominis, which until recently was regarded as a nonpathogenic organism.(Ramirez-Miranda et al., 2011)and (Jimenez-Gonzalez et al., 2012) Several recent studies, however, point to a moderately strong association between $B$ hominis and symptomatic IBS, with some variation between geographic areas.(Yakoob et al., 2010a) and (Grazioli et al., 2006). Certain genotype 1 of the organism shows the closest correlation with IBS.(Yakoob et $a l ., 2010 \mathrm{~b}$ ) In light of growing evidence for an etiologic role for the organism, it appears reasonable to include $B$ hominis in a screening test seeking treatable underlying conditions capable of producing IBS symptoms, particularly because treatment with metronidazole is curative.(Coyle et al., 2012). The finding rate was not agreed $37.75 \%$ that recorded by Hammood et al., 2016 in the same Province, also they recorded high Blastocystis positive rate among IBD than IBS. The variance in the rate mostly due high number of sample 608 stool samples and employee of five lab methods compare to two methods in current study.

Fecal calprotectin is known to be present in stool in neutrophil-mediated inflammation of the intestinal mucosa.(Konikof. 2007) Conversely, in functional disorders such as
IBS, calprotectin levels are typically much lower than those found in inflammatory bowel disease (IBD) and not significantly different from those found in healthy controls.(Tursi et al., 2011) and(Sydora et al., 2012).Van Rheenen et al., 2013 in a metaanalysis of 13 studies from the primary literature, found that in adults being evaluated for IBD, screening by measuring calprotectin levels would produce a $67 \%$ reduction in the number of adults undergoing endoscopy, while only 3 of 33 adults in every 100 who do undergo endoscopy will not have IBD (but would likely have a different condition for which endoscopy is nonetheless inevitable). Conversely, $6 \%$ of adults would have a delay in diagnosis of IBD because of a false negative results.

Remarked GITDs was obvious in current study because 3 of 5 species of protozoan parasites in samples show co-existence with Helicobacter pylori. The invasive Entamoeba histolytica $+H$. pylori leads for producing IBD among some patients enrolling the study. Whereas Blastocystis homini $+H$. pylori and Giardia lamblia $+H$. pylori Co-existence reveal IBS among some patients.

With the protozoan infection co-exists with $H$. pylori the FC positive level or cutoff were fluctuated, it was shown higher with IBS cases versus to slightly lower FC among IBD patients. Controversy to Entamoeba histolytica + H.pylori samples exert FC levels higher than $50 \mathrm{ng} / \mathrm{ml}$. This finding reflects a high grade of injury caused by both microorganisms on GIT.

High mean FC levels close to FC cutoff recording with Entamoeba histolytica and Giardia lamblia, particularly the former parasite which was invasive than the other 3 protozoan parasites in the current study was highlighting alarm of vital impact of parasitic infections in GITDs and exposure the light on 
the role of FC to determine the injury caused to the host by the most infectious agents.

Considering high white blood cell count and neutrophila was indicated to acute infections particularly by Entamoeba histolytica. Whereas high mean FC level among IBD patients was referring to good challenges from the host against intestinal protozoan parasite. According to our information and literatures available in Iraq; the current study was the first in Kirkuk-Iraq concerning with FC, GITDs with protozoan infections and $H$. pylori. So this study was preliminary and the base for future studies.

GITS were health criteria facing scientific workers and gastro-enterologist in Kirkuk Province in particular of IBD and IBS; intestinal protozoan infections may have a role in increasing the rate of gastroenteritis. FC ELISA was good lab tool to assess the degree of injuries in GIT and can be used for predicting GIT cases before and monitoring after endoscopy.

\section{References}

Abd-Alzahra, E.;Shani, W.S and Al-Malak, M.Kh. (2012).Local and systemic

Immune responses in rats infected withGiardia lamblia. Med J. Basrah Univ; 30(1):60-72.

AL-Koze, F.S. Epidemiological study of intestinal parasites among students in primary and secondary school in Bejitown, with study of some biochemical parameters during parasitic infections. M.Sc. thesis Coll. Edu. Tikrit Univ.2011.

Al-Nakkas, E.; AL-Mutar, E.M.; Shweiki, H.M. Sharm, P.N and Rihan, S.Parasitic infection in Kuwait. A study based on primary care center.Med.East. J. Fam.Med.2004; 3:7. Al-Nassiry, M.A. Study of epidemiology of Entamoeba histolytica in Beji town with the study of some herbal extract on the parasite. M.Sc. thesis. Coll. Edu. Tikrit Univ. 2007.

El-safi, S.H.; Al-Magati, Th.N; Hussien, M.I.; Adam,A.M.;Abu-Hassan,

M.M.and Al-Zahrani,E.M. (2013). Comparison of microscopy, rapid immunoassay, and molecular techniques for the detection of Giardialamblia and Cryptosporidium parvum. Parasitol Res; 112:1641-1646.

AL-Zubaydi, B.J.; Mawlood, N.A and Abdullah, N.A. Study the causative agents of diarrhea among children below five years in some regions of Diyala-Iraq. J. Sci AlMustanseryia Univ. 1997; 8(3): 18-24.

Al-Zufri, K. A.S. Epidemiological study of some pathogenic aspects of intestinal parasite among in and out patients attending Al-Najaf Hospitals. M.Sc. Coll. Edu. Kofa Univ. 2004.

Angriman I, Scarpa M, D'IncÌ R. Enzymes in feces: useful markers of chronic inflammatory bowel disease. Clin ChimActa. 2007; 381: 63-68.

Azazy, A.A and Al-Tair, A.S. Study of intestinal and blood parasites among children in Sana Province-Yaman. Saudia Med. J.1999; 20(6): 422-424.

Boorom, K.F., Smith, H., Nimri, L., Viscogliosi, E., Spanakos, G., Parkar, U. Oh my aching gut: irritable bowel syndrome, Blastocystis, and asymptomatic infection. Parasit. Vectors. 2008, 1(1): 40

Chandramathi, S., Suresh, K., Kuppusamy, U.R. Elevated levels of urinary hyaluronidase in humans infected with intestinal parasites. Ann. Trop. Med. Parasitol. 2010, 104(5): 44952.

Chen CC, Huang JL, Chang CJ, Kong MS. Fecal calprotectin as a correlative marker in clinical severity of infectious diarrhea and usefulness in evaluating 
bacterial or viral pathogens in children. J Pediatr Gastroenterol Nutr.2012; 55: 541-547.

Chudnovskiy, Aleksey."Host-Protozoan Interactions Protect from Mucosal Infections through Activation of the Inflammasome". Cell.2016; 167 (2).

Clayton EM, Rea MC, Shanahan F.Carriage of Clostridium difficile in outpatients with irritable bowel syndrome. J Med Microbiol. 2012; 61(9):1290-1294.

Coyle CM, Varughese J, Weiss LM, Tanowitz HB. Blastocystis: to treat or not to treat. Clin Infect Dis. Jan i 2012; 54(1):105110.

Dib, H.H.; Lu, S.Q. and Wen, S.F. Prevalence of Giardia lamblia with or without diarrhea in South East, South East Asia and the Far East. Parasitol

Res.2008. 103(2):239 251.

"Dientamoeba fragilis FAQs". CDC. "Parasites - Dientamoeba fragilis Treatment". CDC. Retrieved December 9, 2016.

Fengming Y, Jianbing W. Biomarkers of inflammatory bowel disease. Dis Markers 2014; 2014.

Foell D, Wittkowski H, Roth J. Monitoring disease activity by stool analyses: from occult blood to molecular markers of intestinal inflammation and damage. Gut.2009; 58: 859-868.

Fox, J. G. 2002. The non-H. Pylori helicobacters: their expanding role in

Gastrointestinal and systemic diseases. Gut 50:273-283.

Friedman S, Blumberg RS.Inflammatory bowel disease. In: Harrison's principles of internal medicine, 17th ed. McGraw Hill, 2008:1886-1899

Grazioli B, Matera G, Laratta C. Giardia lamblia infection in patients with irritable bowel syndrome and dyspepsia: a prospective study. World J Gastroenterol. 2006; 12(12):19414.Hansen LH, Lund C. Amebiasis-a differential diagnosis from inflammatory bowel disease. Ugeskr Laeger. 1998; 160:5514-5515.

Hammood, A.M.; Salman, Y.J.* and Ahmed,B.A. Possible Association between Blastocystis hominis and Bowel Disorders among Iraqi Patients in Kirkuk Province. Int.J.Curr.Res.Aca.Rev.2016; 4(7): 5056

Hamzy, M.; Dabboussi,F.; AL-Ali, K and Ourabi, L. Prevalence of intestinal parasites in Northern Lebanon. Estr.Miditerian Health J. 2003; 10(3): 343-346.

Hestvik E, Tylleskar T, Kaddu-Mulindwa DH, Ndeezi G, Grahnquist L, et al., Helicobacter pylori in apparently healthy children aged 0-12 years in urban Kampala, Uganda: a communitybased cross sectional survey. BMC Gastroenterol.2010; 10: 62.

Ismaiel, M.T.Detection of intestinal parasites among primary shool children in HamaSyria. J. Med.Lab. Diag.2011; 10: 1---9.

Israel DA, Peek RM. Review article: pathogenesis ofHelicobacter pylori induced gastric inflammation. Aliment.Pharmacol Ther 2001; 15: 1271-1290.

Jimenez-Gonzalez DE, Martinez-Flores WA, Reyes-Gordillo J., et al., Blastocystis infection is associated with irritable bowel syndrome in a Mexican patient population. Parasitol Res. Mar 2012; 110(3):1269-1275.

Johnson EH, Windsor JJ, Clark CG. "Emerging from obscurity: biological, clinical, and diagnostic aspects of Dientamoeba fragilis". Clin. Microbiol. Rev.2004; 17 (3): 553-70

Kadir, M. and Salman,Y. Prevalence of intestinal parasites among primary

School in Al- Taameem province, Iraq. Annals of the College of Medicine, Mosul.1999; 25(1 \& 2):94-97. 
Karyaghdi, T.K.N... Study the efficacy of some laboratory methods in diagnosis of intestinal parasite among infected peoples in Kirkuk city-Iraq. M.Sc. thesis, College of Science, Kirkuk University.2013.

Kaya, S., Cetin, E.S., Aridogan, B.C., Arikan, S., Demirci, M. 2007. Pathogenicity of Blastocystis hominis, a clinical reevaluation. Turkiye Parazitol. Derg, 31(3): 184-7.

Kaser A, Zeissig S, Blumberg RS (2010) inflammatory bowel disease. Annu Rev Immunol 28:573-621.

Konikoff MR, Denson LA. Role of fecal calprotectin as a biomarker of intestinal inflammation in inflammatory bowel disease. Inflamm Bowel Dis. 2006; 12(6):524-

Komraus M, Wos H, Wiecek S, Kajor M, Grzybowska-Chlebowczyk U. Usefulness of faecal calprotectin measurement in children with various types of inflammatory bowel disease. Mediators Inflamm2012: 608249.

Lagacé-Wiens PR, VanCaeseele PG, Koschik C "Dientamoeba fragilis: an emerging role in intestinal disease". CMAJ 2006; 175 (5): 468-469.

Langhorst J, Elsenbruch S, Koelzer J, et al., Noninvasive markers in the assessment of

Intestinal inflammation in inflammatory bowel diseases: performance of fecal lactoferrin,

calprotectin, and PMN-elastase, CRP, and clinical indices. Am J Gastroenterol.2008; 162:103-109

Li, L.H., Zhang, X.P., Lv, S. Cross-sectional surveys and subtype classification of human Blastocystis isolates from four epidemiological settings in China. Parasitol. Res.2007, 102: 83-90.

"Parasites - Dientamoeba fragilis - Biology". CDC. Retrieved December 10, 2016.
Ok, U.Z., Girginkardesler, N., Balcioglu, C., Ertan, P., Pirildar, T., Kilimcioglu, AA. Effect of trimethoprim sulfamethaxazole in Blastocystis hominis infection. Am. J. Gastroenterol.1999., 94(11): 32457.

Mack, David. "Dientamoeba fragilis Infection". Emedicine Medscape. Retrieved December 9, 2016

Meyer EA. Human parasitic diseases: giardiasis. In: Meyer EA (ed

Taxonomy and nomenclature. Elsevier, Amsterdam.1990: 51 60....

Morsy,T.A.;Farrag, A.M.; Sabry, A.; Salama, M.M. and Arafa, M.A. Ecto and endoparasites in low primary schools in Qualyob city. Egypt. J.Soc.Parasitol.1991; 21: 391-401.

Munasinghe, V. S.; Vella, N. G.; Ellis, J. T.; Windsor, P. A.; Stark, D."Cyst formation and faecal-oral transmission of Dientamoeba fragilis--the missing link in the life cycle of an emerging pathogen". International Journal for Parasitology. 2013; 43 (11): 879-883.

Nares-Cisneros J, Jaramillo-Rodriguez Y, Martinez-Ordaz VA, VelascoRodriguez VM, Madero A, et al., (2007) Immunochromatographic monoclonal test for detection of Helicobacter pylori antigen in stool is useful in children from high-prevalence developing country. Helicobacter, 2007; 12: 354-358.

Ndao,M. Diagnosis of parasitic diseases: old and new approaches.

Inter-disc Perspect on Infect Dis 2010. 106(5):1127 1134.

Nomura A, Stemermam GN, Chyon PH, et al., Helicobacter pylori infection and gastric carcinoma among JapaneseAmericans in Hawai. N Engl J Med 1995; 325: 1132-1136.

Poirier P, Wawrzyniak I, Vivares CP, Delbac $F$, El Alaoui H. New insights into Blastocystis spp.: a potential link with 
irritable bowel syndrome. PLoS pathogens. 2012; 8(3): 25-45

Qadri, S., Al-Okaili, G.A., Al-Dayel, F. Clinical significance of Blastocystis hominis. J. Clin. Microbiol 1989, 27: 2407- 2409.

Quail MA, Russell RK, Van Limbergen JE, et al., Fecal calprotectin complements routine laboratory investigations in diagnosing childhood inflammatory bowel disease. Inflamm Bowel Dis 2009; 15(5):756 -759.

Raof, Sh., Abdul-Rahman, N.H. 2011. Prevalence of Blastocystis hominis and Giardia lamblia parasites in patients of four regions in East South Baghdad. Iraqi J. Vet. Med., 35(2): 74 84RamirezMiranda ME, Jimenez-Gonzalez DE, Rodriguez-Campa ME.Irritable Bowel Syndrome: Frequency and phylogenetic relationship of Blastocystis spp. from Mexican patients. Rev Gastroenterol Mex. 2011; 76(4):309-315.

Roberts, T., Stark, D, Harkness, J., Ellis J. Subtype distribution of Blastocystis isolates identified in a Sydney population and pathogenic potential of Blastocystis. Eur. J. Clin. Microbiol. Infect. Dis.2013, 32: 335-343.

Salman,Y.J. and Ali,L.S.(2013).detection of some microbial infection among

Children aging below 2 years in Kirkuk city. $\mathrm{J}$ Kirkuk Med Coll; 1(1):53-60.

Salman, Y.J., Mustafa, M.I. Evaluation of the employment of four laboratory diagnostic Giardia lamblia among children in Kirkuk city. J. Kirkuk Med. Coll.2013, 1(2): 52-60.

Salman, Y.J. 2015a. Detection of Blastocystis hominis among Peoples in Kirkuk Province Using ELISA and Direct Microscopy". Int. J. Curr. Microbiol. App. Sci., 4(10): 686-695).

Salman, Y.J. 2015b.; Sadek, W.S. and Rasheed, Z.Kh. Prevalence of Cryptosporidium parvum among Iraqi displaced people in Kirkuk city using Direct microscopy, flotation technique and ELISA_copro-antigen test Int.J.Curr.Microbiol.App.Sci (2015) 4(11): 559-572..

Salman, Y.J.;Al-Taee, A.A. and Mohammad, A.A. Role the Employee of Some Biological Stains in Detecting Giardia lamblia among Internal Iraqi Displaced Peoples in Kirkuk ProvinceInt.J.Curr.Microbiol.App.Sci (2016) 5(3):705-718.

Sayel, Y. K. Prevalence of intestinal parasites among children in Baghdad. M.Sc. thesis. Coll.Sci. Bagh dad Univ. 2005.

Shenin, W.DH. Epidemiology of intestinal parasites among primary school and peoples in ALfohood-Jebayiesh townNasiriya governorate. M.Sc. thesis. Coll.Sci. Basrah Univ. 2005. Sherwood RA. Faecal markers of gastrointestinal inflammation. J Clin Pathol.2012; 65: 981-985.

Stark D, Beebe N, Marriott D, Ellis J, Harkness J. "Prospective study of the prevalence, genotyping, and clinical relevance of Dientamoeba fragilis infections in an Australian population". J. Clin. Microbiol.2005; 43 (6): 271823.

Stensvold, J.R. 2013. Blastocystis: Genetic diversity and molecular methods for diagnosis and epidemiology Trop Parasitol. 2013 Jan-Jun; 3(1): 26-34.

Suerbaum S, Josenhans. C. Helicobacter pylori evolution and phenotypic diversification in a changing host. Nat Rev Microbiol 5: 441-452.

Sydora MJ, Sydora BC, Fedorak RN. Validation of a point-of-care desk top device to quantitate fecal calprotectin and distinguish inflammatory bowel disease from irritable bowel syndrome. J Crohns Colitis. 2012; 6(2):207-214. 
Tachezy, Jan: Hydrogenosomes and mitosomes: mitochondria of anaerobic eukaryotes ISBN 978-3-642-09542-9.

Tursi A, Elisei W, Giorgetti G, Aiello F, Brandimarte G. Role of fecal calprotectin in the diagnosis and treatment of segmental colitis associated with diverticulosis. Minerva Gastroenterol Dietol. 2011; 57(3):247255

Van Rheenen PF, Van de Vijver E, Fidler V. Faecal calprotectin for screening of patients with suspected inflammatory bowel disease: diagnostic meta-analysis. BMJ 2010; 341.

Xiao, L., Escalante, L., Yang, C. (1999).Phylogenetic analysis of

Cryptosporidium parasites based onthe small sub-unit rRNA. Genelocus.Appl. Environ. Microbial.1999. 65: 15781583.Clinical and Laboratory Standard Institute (CLSI). Procedures for therecovery and identification of parasites from the intestinal tract; approved guidelines second edition. 2005. M28-A2 (ISBN 1-56238-572-0).

Yakoob J, Jafri W, Beg MA., et al., Blastocystis hominis and Dientamoeba fragilis in patients fulfilling irritable bowel syndrome criteria. Parasitol Res. Aug 2010; 107(3):679-684.

Yakoob J, Jafri W, Beg MA., et al., Irritable bowel syndrome: is it associated with genotypes of Blastocystis hominis.
Parasitol Res. Apr 2010; 106(5):10331038.

Yoshikawa, H., Abe, N., Iwasawa, M. 2004. Fecal-oral transmission of the cyst form of Blastocystis hominis in rats. Parasitol. Res., 94(6): 391-396.

Youssef, M.; Shurman, A, Bougnoux, M.; Rawashdeh,M.; Bretange, $\mathrm{S}$ and Strockbine, N. Bacterial, viral and parasitic enteric pathogens associated with acute diarrhea in hospitalized children from North Jordon. FFMS Immunol.Med. Microbiol.2000; 28: 257-263.Wensaas, K.A.; Langeland, N.; Hanevik, K.; Morch. K.; Eide, G.E. and Rorteveit, G. Irritable bowel syndrome and chronic fatigue 3 years after acute giardiasis: historic cohort study. Gut. 2012; 61(2): 214-219.

World Health Organization. Basic laboratory methods in medical

parasitology.W.H.O Geneva.1991:16-17.

World Health Organization.Manual to medical laboratory investigations.2003

WHO Geneva.

Wilson, S., Roberts, L., Roalfe A., Bridge P., Singh S. 2004. Prevalence of irritable bowel syndrome: a community survey. Br. J. Gen. Pract., 54: 495-502.

Windsor JJ, Macfarlane L. "Irritable bowel syndrome: the need to exclude Dientamoeba fragilis". Am. J. Trop. Med. Hyg. 2005; 72 (5): 501; author reply 501-2. PMID 15891119

\section{How to cite this article:}

Yahya Jirjees Salman, Chateen Aizideen Ali and Adil Abdu Allah Abdul Razaq. 2017. Fecal calprotectin among patients infected with some protozoan infections. Int.J.Curr.Microbiol.App.Sci. 6(6): 3258-3274. doi: http://doi.org/10.20546/ijcmas.2017.606.384 